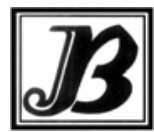

J. bio-sci. 20: 75-82, 2012

ISSN 1023-8654

http://www.banglajol.info/index.php/JBS/index

\title{
COMPARATIVE STUDY ON GROWTH AND MORPHOLOGICAL CHARACTERISTICS OF A WILD TYPE STRAIN RHIZOBIUM SPP. (RCA-220) AND A GENETICALLY ENGINEERED E. COLI BL21
}

\author{
M M Rahman*, M Salah Uddin, S Zaman, M A Saleh, A E Ekram, P Farhana, M H Razu \\ Department of Genetic Engineering and Biotechnology, \\ University of Rajshahi Rajshahi-6205, Bangladesh
}

\begin{abstract}
Context: Comparison between a wild type strain Rhizobium spp. (RCA-220) and a genetically modified strain E. coli BL21 in context of growth features.

Objective: To observe the comparative growth characteristics of a genetically modified E. coli BL21 and an isolated wild type strain Rhizobium spp. (RCA-220).

Materials and Methods: Different kinds of investigations were accomplished in both Luria-Bertani (LB) liquid and semi-solid media to observe the growth and maintenance of these strains. For the isolation of Rhizobium spp. selective Yeast Extract Manitol Agar (YEMA) was used. Colony morphology, pH, temperature, carbon source, salt concentration and light were taken under consideration and optimized for growth characteristics.

Results: For the strain E. coli BL21, the maximum growth rate was 1.9 at incubation time $72 \mathrm{~h}, \mathrm{pH} 7.2$, temperature $37^{\circ} \mathrm{C}$ (optimized) while for Rhizobium spp. the growth rate was significantly higher (OD 2) at pH 6.8 , temperature $28^{\circ} \mathrm{C}$ (optimized). Among all used carbon sources, strains grown in the medium supplemented with peptone showed rapid and good performance. So, peptone was proved as the best carbon source for both strains. The maximum growths of these strains were observed at $0 \mathrm{~g} / 100 \mathrm{ml} \mathrm{NaCl}$ salt concentration. RCA-220 strain was comparatively more tolerable to salt than $E$. coli BL21 strain. In this work, $E$. coli BL21 showed rapid and good performance in presence of light while Rhizobium spp. showed better performance in absence of light. Statistical analysis showed that the growth rate of Rhizobium spp. was significantly higher than $E$. coli BL21.

Conclusion: From the experimental results, it can be concluded that naturally obtained microbial strains were stable and could tolerate any stress condition where the modified strains lose their growth capability and the overall growth performances were reduced or slowed down than the wild type strain.
\end{abstract}

Key words: Genetically modified, RCA-220, Optimization, Morphological parameters.

\section{Introduction}

Bacteria are a large domain of prokaryotic microorganisms which can grow in soil, acidic hot springs, radioactive waste, root nodules of plants (Fredrickson et al. 2004). Most bacteria have not been characterized yet and only a few species can be grown in the laboratory (Rappe and Giovannoni 2003). Rhizobium belongs to the family Rhizobiaceae and found in soil and root nodules on leguminous plants and benefits the plant by nitrogen fixation (Lodwig et al. 2003). Escherichia coli is a Gram-negative, rod-shaped bacterium that is commonly found in the lower intestine of warm-blooded organisms (endotherms). E. coli belongs to the family Enterobacteriaceae and is the most widely studied prokaryotic model organism (Keseler et al. 2005). It was one of the first organisms to have its genome sequenced; the complete genome of $E$. coli K12 was published by Science in 1997 (Blattner et al.1997).

*Corresponding author E-mail: Jhinuk_geb@yahoo.com 
E. coli BL21 is an engineered strain and is the most widely used for high-yield expression of recombinant protein (Sorensen and Mortensen 2005). In E. coli BL21 several modifications have performed like addition of T7 RNA polymerase gene and transduction of the "malB region" from the K-12 strain W3110 to make the strain Mal ${ }^{+} \lambda^{S}$ (Studier et al. 2009). E. coli BL21 is a very versatile host for the production of heterologous proteins (Cornelis 2000), and various protein expression systems have been developed which allow the production of recombinant proteins. Researchers can introduce genes into the microbes using plasmids which permit high level expression of protein. As E. coli BL21 is a modified strain, so there would be significant difference between engineered and wild type strain. The differences may be in growth rate, carbon accumulation, growth temperature etc. In this research work, we used the genetically engineered $E$. coli BL21 strain and a normal Rhizobium ciceri (RCA-220) that nodulate chickpeas (Cicer arietinum L.) (Nour et al.1994). Considering all these viewpoints, an attempt was made to investigate the growth habit and adaptation capabilities of these bacterial strains under different conditions in the present study.

\section{Materials and Methods}

\section{Isolation and Collection of Materials}

Strain of Rhizobium spp. was obtained from pink colored root nodules of field grown chickpeas in Bangladesh Agricultural Research Institute (BARI). Collected nodules were sterilized in $0.1 \%$ (w/v) sodium hypochlorite $(\mathrm{NaOCl})$ for $5 \mathrm{~min}$ and followed by immersing in $95 \%(\mathrm{w} / \mathrm{v})$ ethanol for $10 \mathrm{sec}$, and then washed five to six times with distilled water. Then the nodules were crushed with the help of sterile forceps and then

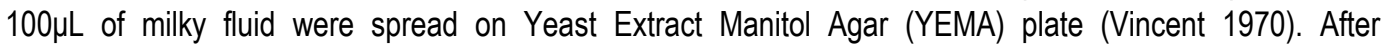
incubation for 3 days at $30^{\circ} \mathrm{C}$, bacterial colonies were found to grow on the medium. Single colony was selected and restreaked on agar plate for purify. E. coli BL21 strain was obtained by the courtesy of Protein Biochemistry Laboratory, Gwangju, South Korea.

\section{Culture Media}

LB (Luria-Bertani) broth and agar medium was used for sub culturing, streaking and plating of these strains. Growth in LB broth incubated at $37^{\circ} \mathrm{C}$ on an orbital shaker at $160 \mathrm{rpm}$ for $96 \mathrm{~h}$ was determined by measuring the optical density (OD) at $660 \mathrm{~nm}$ every $2 \mathrm{~h}$. The generation time was calculated from the logarithmic phase of growth.

\section{Colony Morphology}

Colony morphology was evaluated by streaking a loop of the initial inoculum on LB agar and allowing the bacteria to grow at $37^{\circ} \mathrm{C}$ for 2 to 3 days (Vincent 1970). After 2-3 days of incubation, individual colonies were characterized based on their color, shape and size, and Gram stain reaction. Following plate counting method, cell density of these bacterial strains was calculated.

\section{$\mathrm{pH}$ and Temperature Tolerance}

The media were evaluated according to different $\mathrm{pH}$ variations ranging from $0-10$ and tolerance to high temperatures were tested by typing on $\mathrm{LB}$ broth and incubating at $10^{\circ} \mathrm{C}, 15^{\circ} \mathrm{C}, 20^{\circ} \mathrm{C}, 25^{\circ} \mathrm{C}, 30^{\circ} \mathrm{C}, 35^{\circ} \mathrm{C}$, $40^{\circ} \mathrm{C}, 45^{\circ} \mathrm{C}$ and $50^{\circ} \mathrm{C}$.

\section{Growth with Different Carbon Sources}

In this research work glucose, glycerol, peptone and sugar were used as carbon sources. Paliy and Gunasekera (2007) suggested that equal concentration of carbon sources is required for obtaining standard result. Following this suggestion, $10 \mathrm{~g} / \mathrm{L}$ carbon sources were added to the medium used in the present study. 


\section{Effect of Sodium Chloride ( $\mathrm{NaCl}$ ) and Light}

The ability of these strains to grow in different concentrations of salt was tested by streaking strains on LB agar medium containing $0,5,10,15$ and $20 \mathrm{~g}$ per $100 \mathrm{ml} \mathrm{NaCl}$ concentration. The effect of light on the growth of these strains was also observed using LB broth.

\section{Statistical Analysis}

Different statistical approaches such as variance, standard deviation and co-efficient of variation were used as statistical analysis in the present study.

$$
\text { Formula: }
$$

$$
\begin{aligned}
& \text { Variance, } \sigma^{2}=\sum_{\bar{i}=1}^{n} \frac{\left(x_{i}-\bar{x}\right)^{2}}{n} \\
& \text { Standard deviation, } \sigma=\sqrt{\sum_{i=1}^{n} \frac{\left(x_{i}-\bar{x}\right)^{2}}{n}} \\
& \text { Co-efficient of variation, } \mathrm{CV}=\frac{\bar{g}}{\bar{x}}
\end{aligned}
$$

\section{Results}

The bacterial strains were inoculated in LB media to observe their growth efficiency. The highest and the lowest growth rate were observed in $72 \mathrm{~h}$ and $0 \mathrm{hr}$, respectively. The decline phase was observed in $96 \mathrm{~h}$ (Fig. 1). Colony of E. coliBL21 was transparent, round shaped and white in color (Fig. 2) while Rhizobium spp. was opaque, compact, sticky, granule shaped and off-white in color (Fig. 3). Both E. coliBL21 and Rhizobium spp. were Gram negative rod shaped bacteria and following plate counting method, the cell density of these strains were $5.76 \times 10^{10}$ and $1.16 \times 10^{15}$ cells/ $/$ l, respectively. Both the strains were grown in LB medium with $\mathrm{pH}$ values ranging from 0 - 10 and the maximum growth was observed at pH ranging from 6 to 8 (Fig. 4). Further, the research work was extended to optimize the pH variation and for $E$. coliBL21, the maximum growth was found at pH 7.2 (Fig. 5) while Rhizobium spp. showed maximum growth at pH 6.8 (Fig. 5).

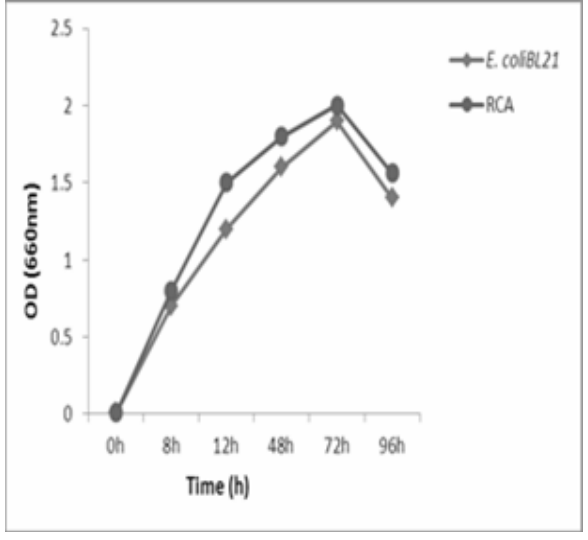

Fig.1. The growth habit of E. coliBL21 and Rhizobium spp. (RCA-220) at regular time intervals.

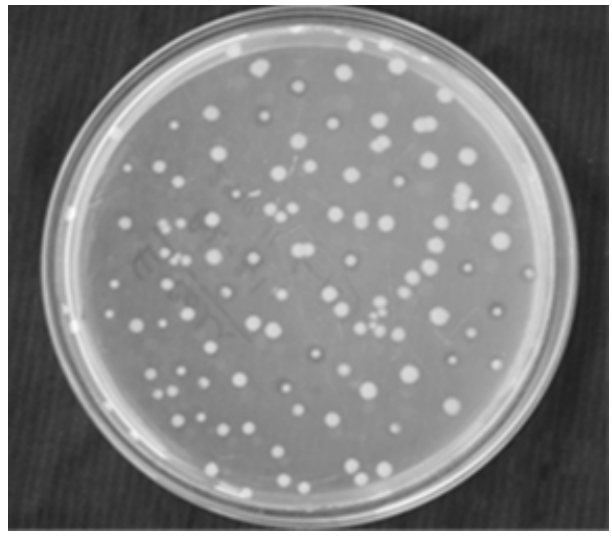

Fig.2. Plate showing the colony nature of E. coli BL21. 


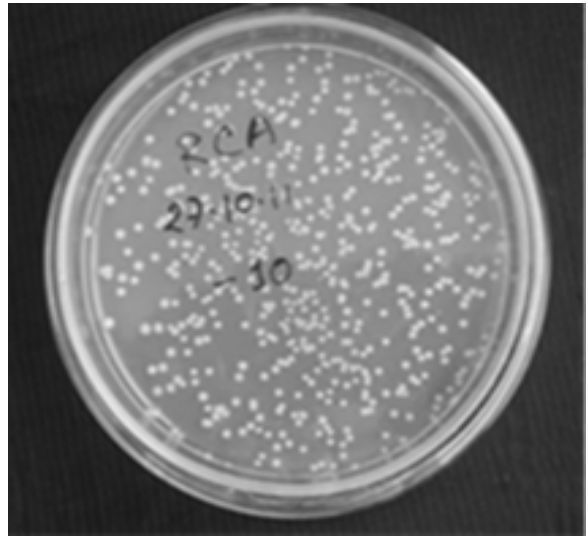

Fig. 3. Plate showing the colony nature of Rhizobium spp. (RCA-220).

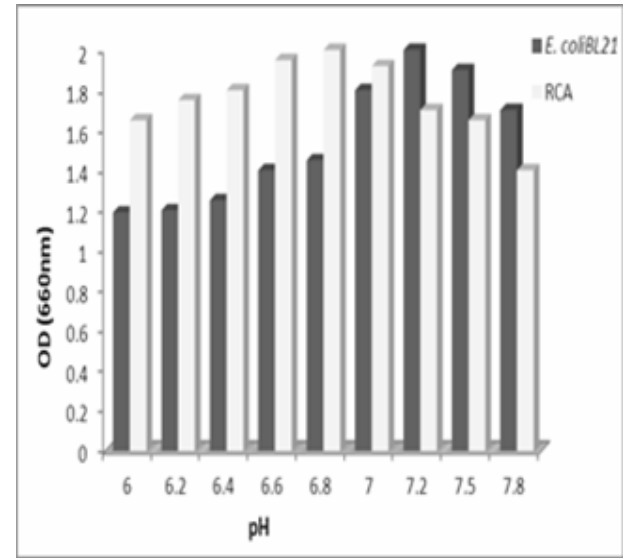

Fig. 5. Growth rates of $E$. coli BL21 and Rhizobium spp. (RCA-220) in $48 \mathrm{~h}$ of incubation period in optimum $\mathrm{pH}$.

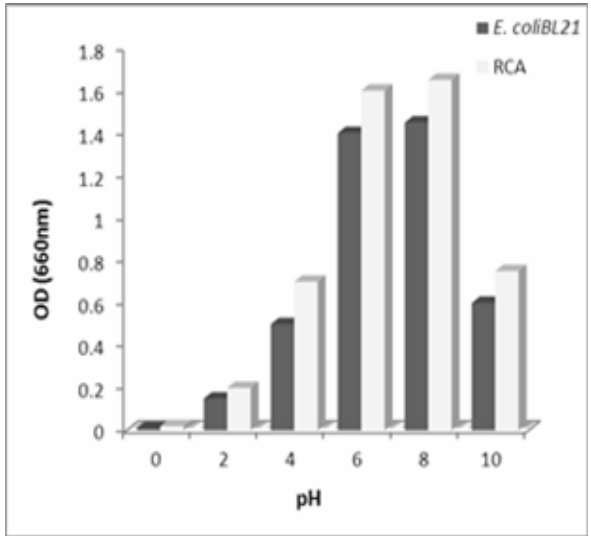

Fig. 4. Effect of $\mathrm{pH}$ variations on the growth of $E$. coli BL21 and Rhizobium spp. (RCA-220) in 24h of incubation period.

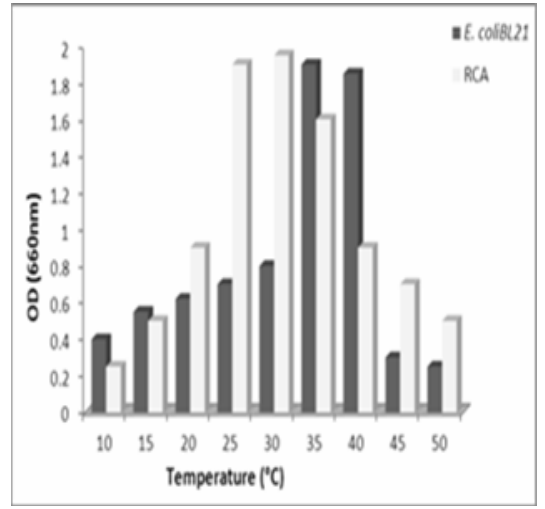

Fig. 6. Growth rates of $E$. coli BL21 and Rhizobium spp. in $48 \mathrm{~h}$ of incubation in LB media with the variations of temperature. 


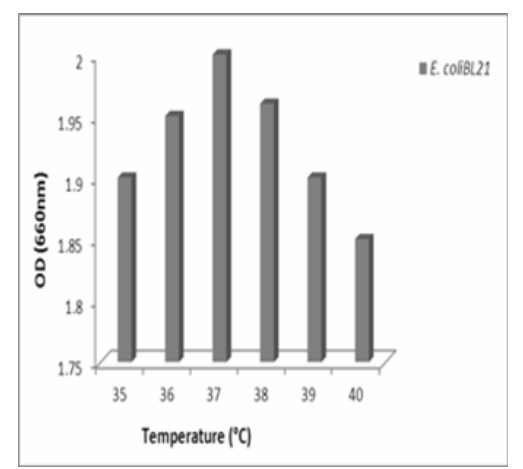

Fig. 7. Growth rates of $E$. coli $\mathrm{BL} 21$ in $48 \mathrm{~h}$ of incubation in LB media in optimum temperature.

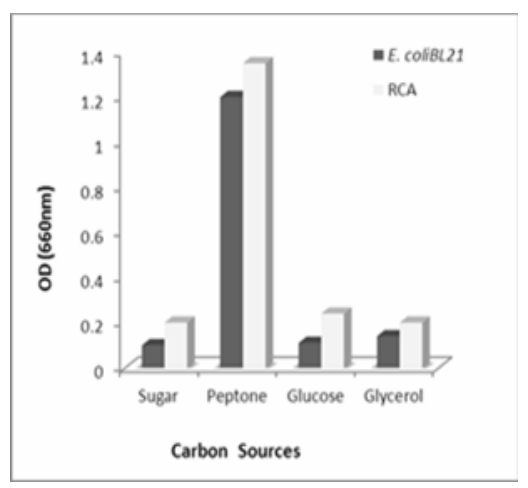

Fig. 9. Growth rates of $E$. coli BL21 and Rhizobium spp. (RCA-220) in $72 \mathrm{~h}$ of incubation period in different carbon sources.

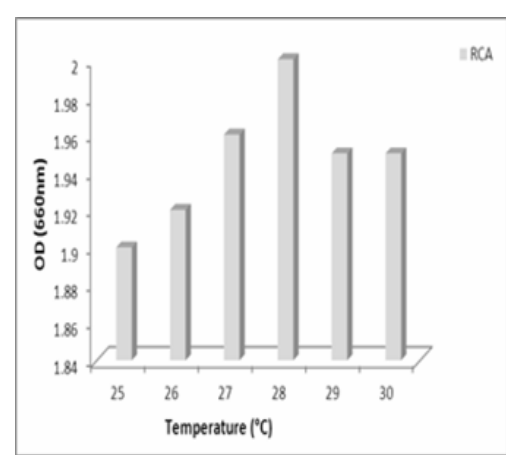

Fig. 8. Growth rates of Rhizobium spp. (RCA-220) in $48 \mathrm{~h}$ of incubation in LB media in optimum temperature.

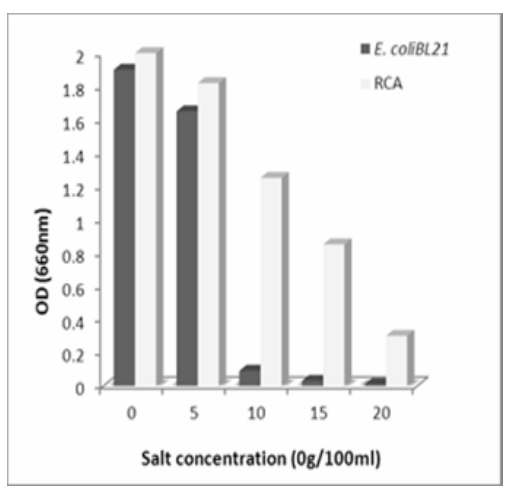

Fig. 10. Growth rates of $E$. coli BL21 and Rhizobium spp. (RCA-220) in $24 \mathrm{~h}$ of incubation period in different salt concentrations.

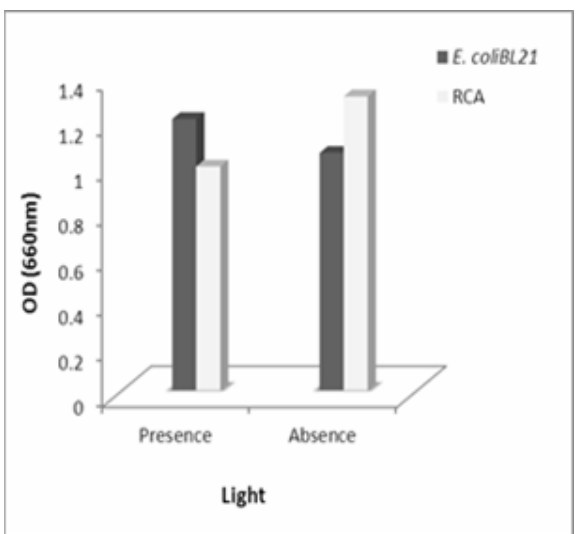

Fig. 11. Growth rates of E. coli BL21 and Rhizobium spp. (RCA-220) in 12h of incubation period in the presence and absence of light. 
E. coli BL21 showed better performance at $35^{\circ}-40^{\circ} \mathrm{C}$ (Fig. 6) and Rhizobium spp. showed better growth at $25^{\circ}-30^{\circ} \mathrm{C}$ (Fig. 6). Then, the research work was extended to optimize the temperature variation and for $E$. coliBL21 the highest growth was found at $37^{\circ} \mathrm{C}$ (Fig. 7) while the maximum growth of Rhizobium spp. was found at $28^{\circ} \mathrm{C}$ (Fig. 8). The growth of these strains at different carbon sources was assessed and it was observed that peptone containing medium showed maximum growth (Fig. 9). On the other hand, strains grown in the medium containing sugar, glucose and glycerol showed poor and slow growth performance. The effect of salt on the growth of these strains was observed and maximum growth was found at $0 \mathrm{~g} / 100 \mathrm{ml} \mathrm{NaCl}$ salt concentration (Fig. 10). In this work, E. coli BL21 showed rapid and good performances in presence of light while Rhizobium spp. showed better performance in absence of light (Fig. 11). It is also found that the overall growth performance of Rhizobium spp. is greater than the engineered E. coliBL21. The growth superiority of Rhizobium spp. is also confirmed by statistical analysis like calculation of variance $\left(\sigma^{2}\right)$, standard deviation $(\sigma)$ and coefficient of variation $(\mathrm{CV})$. At optimum culture conditions (optimized $\mathrm{pH}$, temperature, carbon sources, salt concentration and light) all the CVs for Rhizobium spp. is smaller than the CVs for E. coli BL21 which proves that the growth of Rhizobium spp. followed normal distribution and its growth rate is better than E. coli BL21 (Table 1).

Table 1. Estimation of variance, standard deviation and co-efficient of variation by the $O D$ of $E$. coliBL21 and Rhizobium spp. that grew at optimum culture condition, $\sigma^{2} E$ indicate the variance of $E$. coliBL21 and $\sigma^{2} \mathrm{R}$ indicate the variance of Rhizobium spp. (RCA-220).

\begin{tabular}{|c|c|c|c|c|c|c|}
\hline \multirow{2}{*}{$\begin{array}{c}\text { Growth } \\
\text { conditions }\end{array}$} & \multicolumn{2}{|c|}{ Variance $\left(\sigma^{2}\right)$} & \multicolumn{2}{c|}{ Standard deviation $(\sigma)$} & \multicolumn{2}{c|}{ Co-efficient of variation (CV) } \\
\cline { 2 - 6 } & $\sigma^{2} E$ & $\sigma_{E}$ & $\sigma_{R}$ & $\sigma_{E}$ & $C_{R}$ \\
\hline pH & 0.5772 & 0.6603 & 0.7597 & 0.8126 & 0.8340 & 0.8134 \\
\hline Temperature & 0.4972 & 0.5688 & 0.7051 & 0.7542 & 0.8315 & 0.8145 \\
\hline Carbon sources & 0.1912 & 0.3120 & 0.4373 & 0.5585 & 0.8942 & 0.8178 \\
\hline $\begin{array}{c}\text { Salt } \\
\text { concentration }\end{array}$ & 0.4922 & 0.5634 & 0.7073 & 0.7506 & 0.8282 & 0.8079 \\
\hline Light & 0.4294 & 0.4897 & 0.6553 & 0.6998 & 0.7489 & 0.7297 \\
\hline
\end{tabular}

\section{Discussion}

In this research work, both strains showed the highest growth rate in $72 \mathrm{~h}$, while the lowest growth rate was in $0 \mathrm{~h}$ and the decline phase in 96h. The similar findings have also been reported by Nguyen (2006). Rhizobium spp. (RCA- 220) showed better growth performance than E. coli BL21 at regular time intervals (Fig. 1). Differences and similarities between two strains were verified using some morphological parameters like shape, size and color. Kucuk et al. (2006) reported that the colony of Rhizobium spp. is opaque, granule shaped and off-white in color which matches the results of the present study. Considering the cell density of both strains, it is generally comparable that the multiplication ability of Rhizobium spp. was much higher than the modified E. coli BL21. It was reported that the E. coli BL21 grew better at pH 6, 7 and 8 and did not grow at pH 4 and 5 (Schilling 2008), but moderate growth was observed at pH 4, 5 and 10. Similarly, in case of Rhizobium spp., reported poor growth was detected at pH 3 and 9 (Kucuk and Kivanc 2008), but moderate growth at pH 10 was found in this research. Both the strains were tolerant at high temperature (Fig. 6) (Soussi et al. 2001) and either lower or higher temperature could stall cell growth (Zhu 2007). Previous research of Thakur et al. (2010) reported that $E$. coliBL21 showed maximum growth in glycerol supplemented medium but in this research work, among all the 
used carbon sources, peptone containing medium showed the rapid and good performance on growth at regular time intervals and the cell density was 1.2 after $72 \mathrm{~h}$ of incubation (Fig. 9). The present study observed that Rhizobium spp. also showed the best performance on growth in peptone supplemented medium (Fig. 9) and the optical density was 1.4. Considering both strains, it was found that the growth rate of Rhizobium spp. was significantly higher than $E$. coli BL21. Both strains showed a significant increase in growth at $0 \mathrm{~g} / 100 \mathrm{ml} \mathrm{NaCl}$ salt concentrations (Abdulkarim et al. 2009). With further increase in the $\mathrm{NaCl}$ concentration, growth was found to steadily decrease but interestingly, Rhizobium spp. was able to grow in $\mathrm{NaCl}$ as high as $10 \mathrm{~g} / 100 \mathrm{ml}$ concentration indicating as more tolerant than $E$. coli BL21. Rationale from this finding agreed that $E$. coliBL21 was a modified strain and unable to grow in natural condition, whereas Rhizobium spp. occurred in soil and were better adapted in natural conditions like salinity. In case of light, we found that $E$. coli BL21 grew better in presence of light but Rhizobium spp. responded well in absence of light. Key finding was that naturally occurring Rhizobium spp. showed better growth performances in absence of light as the strain lives in or under the soil where light is not available.

\section{Conclusion}

From the above discussions it can be concluded that, if a bacterial strain is modified ( $E$. coli BL21) its overall growth performance become reduced than a normal bacterial strain (Rhizobium spp.). As certain genetic elements have been changed or removed by genetic engineering techniques to modify a bacterium might lead to its slow growth rate. The obtained results may help the researchers to know further differences and similarities between engineered bacteria and normal bacterial strain and the information might be valuable for researchers to do future experiments in the field of microbiology.

\section{References}

Abdulkarim SM, Fatimah AB, Anderson JG. 2009. Effect of salt concentrations on the growth of heat-stressed and unstressed Escherichia coli. JFAE 7 (3\&4), 51 - 54.

Blattner FR, Plunkett G, Bloch CA, Perna NT, Burland V, Riley M, Vides JC, Glasner JD, Rode CK, Mayhew GF, Gregor J, Davis NW, Kirkpatrick HA, Goeden MA, Rose DJ, Mau B, Shao Y. 1997. The complete genome sequence of Escherichia coli K-12. Science 277 (5331), 1453-1462. http://dx.doi.org/10.1126/science.277.5331.1453

Cornelis P. 2000. Expressing genes in different Escherichia coli compartments. Curr Opin Biotech 11 (5), 450-454. http://dx.doi.org/10.1016/S0958-1669\%2800\%2900131-2

Fredrickson JK, Zachara JM, Balkwill DL, Kennedy D, Li SW, Kostandarithes HM, Daly MJ, Romine MFR, Brockman FJ. 2004. Geomicrobiology of high-level nuclear waste-contaminated vadose sediments at the Hanford site, Washington State. App Environ Microbiol 70 (7), 4230-41. http://dx.doi.org/10.1128/AEM

Keseler IM, Vides JC, Castro SG, Ingraham J, Paley S, Paulsen IT, Gil1 MP, Karp PD. 2005. Eco Cyc: a comprehensive database resource for Escherichia coli. Nucleic Acids Res 33. http://dx.doi.org/10.1093/nar/gki108

Kucuk C and Kivanc M. 2008. Preliminary characterization of Rhizobium strains isolated from chickpea nodules. Afr J Biotech 7 (6), 772-775.

Kucuk C, Kivanc M, Kinaci E. 2006. Characterization of Rhizobium sp. isolated from bean. Turk J Biol 30, 127-132.

Lodwig EM, Hosie AHF, Bourdes A, Findlay K, Allaway D, Karunakaran R, Downie JA, Poole PS. 2003. Amino-acid cycling drives nitrogen fixation in the legume-Rhizobium symbiosis. Nature 422, 722-726. http://dx.doi.org/10.1038/nature01527

Nguyen MT. 2006. The effect of temperature on the growth of the bacteria Escherichia coli DH5a. Saint Martin's University Biology Journal Volume 1.

http://www.stmartin.edu/fac_staff/molney/website/SMU Bio Journal/Nguyen 2006.pdf

Nour SM, Fernandez MAP, Normand P, Marel JCC. 1994. Rhizobium ciceri sp. nov., consisting of strains that nodulate chickpeas (Cicer arietinum L.). Int J Syst Bacteriol 44 (3), 511-522. http://dx.doi.org/10.1099/00207713-44-3-511 
Paliy $O$ and Gunasekera TS. 2007. Growth of E. coliBL21 in minimal media with different gluconeogenic carbon sources and salt contents. Appl Microbiol Biotechnol 73, 1169-1172. http://dx.doi.org/10.1007/s00253-006-0554-8

Rappe MS and Giovannoni SJ. 2003. The uncultured microbial majority. Annu Rev Microbiol 57, 369-394. http://dx.doi.org/10.1146/annurev.micro.57.030502.090759

Schilling AT. 2008. The effect of pH on the bacterium E. coli. California State Science Fair 2008 Project Summary. http://www.usc.edu/CSSF/History/2008/Projects/J1429.pdf

Sorensen HP and Mortensen KK. 2005. Soluble expression of recombinant proteins in the cytoplasm of Escherichia coli. Microb Cell Fact 4, 1. http://dx.doi.org/10.1186/1475-2859-4-1.

Soussi M, Santamara M, Ocana A, Lluch C. 2001. Effects of salinity on protein and lipopolysaccharide pattern in a salt tolerant strain of Mesorhizobium ciceri. J Appl Microbiol 90, 476-481. http://dx.doi.org/10.1046/.1365-2672.2001.01269.x

Studier. 2009. Stratagene E. coli Genotype Strains. J Mol Biol 394 (4), 653.

Thakur CS, Brown ME, Sama JN, Jackson ME, Dayie TK. 2010. Growth of wild type and mutant E. coli strains in minimal media for optimal production of nucleic acids for preparing labeled nucleotides. Appl Microbiol Biotechnol 88, 771779. http://dx.doi.org/10.1007/s00253-010-2813-y. Epub 2010 Aug 21.

Vincent JM. 1970. A manual for the practical study of root nodulebacteria. Oxford: [Published for the] International Biological Programme [by] Blackwell Scientific p. 164. http://dx.doi.org/10.1002/jobm.19720120524.

Zhu Y. 2007. The effects of $\mathrm{pH}$ and temperature on the growth of Escherichia coliDH5a. California State Science Fair 2007 Project Summary. http://www.usc.edu/CSSF/History/2007/Projects/J14.pdf. 